\title{
Análise histológica da cicatrização da anastomose colônica, em ratos, sob ação de enema de Aroeira-do-sertão (Myracrodruon urundeuva fr. all.) a $10 \%{ }^{1}$
}

\author{
Histologic analysis of colonic anastomotic healing, in rats, under the action of $10 \%$ \\ Aroeira-do-sertão (Myracrodruon urundeuva fr. all.) enema.
}

\author{
Annya Costa Araújo de Macedo Goes ${ }^{2,}$ Lusmar Veras Rodrigues ${ }^{3}$, Dalgimar Beserra de Menezes ${ }^{4}$,Maria do Patrocínio \\ Ferreira Grangeiro $^{5,}$ Antônio Rubens Martins Soares Cavalcante ${ }^{6}$
}

1. Trabalho realizado no Laboratório de Cirurgia Experimental do Departamento de Cirurgia da Universidade Federal do Ceará, Programa de Pós-Graduação stricto sensu em Cirurgia, Faculdade de Medicina, Departamento de Cirurgia da Universidade Federal do Ceará (UFC), Brasil.

2. Mestranda em Cirurgia do Departamento de Cirurgia, UFC, Fortaleza, CE.

3. Professor Livre-docente, Doutor do Departamento de Cirurgia e do Programa de Pós-Graduação em Cirurgia da Universidade Federal do Ceará.

4. Professor Livre-docente do Departamento de Patologia e Medicina Legal da Universidade Federal do Ceará.

5. Professora Substituta do Departamento de Patologia e Medicina Legal, UFC, Fortaleza, CE.

6. Mestrando em Cirurgia do Departamento de Cirurgia, UFC, Fortaleza, CE.

\section{RESUMO}

Objetivo: Avaliar, do ponto de vista histológico, a ação do extrato aquoso da aroeira-do-sertão na cicatrização da anastomose colônica, em ratos Wistar. Métodos: Foram utilizados 48 ratos da linhagem Wistar, machos, com peso médio de $320 \mathrm{~g}$, distribuídos em dois grupos, com 24 animais, cada. Todos os animais foram submetidos à secção transversa completa do cólon descendente, seguida de anastomose colônica. Os ratos do grupo A receberam diariamente no pós-operatório enemas de veículo à base de carboximetilcelulose (CMC). Os animais do grupo B receberam no pós-operatório enemas de extrato aquoso de aroeira-do-sertão a 10\% em veículo à base de CMC, até a data da eutanásia. Nas datas 3, 7, 14 e 21 do experimento, seis ratos de cada grupo foram submetidos à remoção de segmento colônico, incluindo a anastomose, destinado à apreciação histológica e análise qualitativa da resposta celular inflamatória e cicatricial. Resultados: A análise morfológica revela diferença significante entre os grupos, no dia 7 ( $\tilde{n}<0,05)$, quando o grupo estudado apresentou menor escore que o grupo controle. A deposição do colágeno no grupo aroeira foi menor, nos dias 3, 7 e 14 (ñ < 0,05), em relação ao grupo controle. Conclusão: O extrato aquoso da aroeira-do-sertão tem ação antiinflamatória. Também possui efeito inibitório na deposição do colágeno nas fases inflamatória e de fibroplasia no processo cicatricial de anastomoses colônicas, em ratos Wistar, porém em fases avançadas (dia 21) a cicatrização se dá de forma semelhante aos animais do grupo controle.

Descritores: Cirurgia Colorretal. Cicatrização de Feridas. Fitoterapia.

\begin{abstract}
Purpose: Evaluate, from a histologic view point, the action of the aqueous extract of aroeira-do-sertão on the healing of colonic anastomosis, in Wistar rats. Methods: There were used 48 Wistar rats, males, with average weight of $320 \mathrm{~g}$, distributed in two groups, with 24 animals, each. All animals were subjected to a complete transverse section of the descending colon, followed by colonic anastomosis. The rats on group A received daily post-operative enemas of carboxymethylcellulose (CMC) based vehicle. The animals on group B received post-operative enemas of $10 \%$ aqueous extract of aroeira-do-sertão in CMC based vehicle, until the date of euthanasia. On days 3, 7, 14 and 21 of the experiment, six rats in each group were subjected to removal of a colonic segment, including the anastomosis, destined to histological evaluation and qualitative analysis of inflammatory and healing cell response. Results: The morphologic analysis reveals a significant difference between groups, on day $7(\tilde{\mathrm{n}}<0,05)$, when the group studied showed lower score than the control group. The collagen deposition on the aroeira group was lower, on days 3 , 7 and $14(\tilde{\mathrm{n}}<0,05)$, compared to the control group. Conclusion: The aqueous extract of aroeira-do-sertão has anti-inflammatory action. It also has inhibitory effect on collagen deposition during the phases of inflammation and fibroplasia of the healing process of colonic anastomoses, in Wistar rats, but in advanced phases (day 21) the healing process is similar to that in the animals of the control group.
\end{abstract}

Key Words: Colorectal Surgery. Wound healing. Phytotherapy. 


\section{Introdução}

Os procedimentos cirúrgicos para doenças dos cólons são comuns na prática médica. Nos últimos dois séculos, a cicatrização de anastomoses intestinais vem sendo estudada em seus mais diversos aspectos.

As deiscências de anastomoses colônicas ocorrem com maior freqüência que aquelas no intestino delgado e podem determinar elevadas taxas de morbidade e mortalidade $^{1}$. Complicações relacionadas a anastomoses intestinais são mais observadas durante a primeira semana de pós-operatório, quando a força de tensão anastomótica depende da habilidade dos componentes da matriz extracelular, particularmente das fibras colágenas da submucosa, em reter a sutura. Após este período inicial, a força de tensão é restaurada de forma semelhante ao tecido são, através da deposição de novas fibras colágenas produzidas pelos fibroblastos sob o comando do sistema imune celular e humoral ${ }^{2}$. Esse processo de cicatrização de feridas compreende três fases distintas: hemostasia e inflamação, fibroplasia e maturação ou remodelagem³ ${ }^{3}$.

A cicatrização inadequada de anastomoses intestinais pode ter diversas causas, englobando aspectos relativos ao paciente e à técnica operatória. Fatores que sabidamente interferem na cicatrização e na integridade das anastomoses colônicas são: suprimento sangüíneo, resposta individual, técnica e cuidados cirúrgicos, flora bacteriana, inflamação, idade, estado nutricional, doenças associadas e drogas ${ }^{1,4}$.

A influência de outros fatores sobre a cicatrização de anastomoses colônicas tem sido investigada. As drogas antiinflamatórias têm despertado especial interesse dos pesquisadores por terem o potencial de interferir nas fases de inflamação e fibroplasia do processo cicatricial ${ }^{4,5}$.

No Nordeste do Brasil, mais especificamente no Estado do Ceará, é de uso popular a entrecasca da aroeira-dosertão (Myracrodruon urundeuva Fr. AlI. ou Astronium urundeuva engl.), planta da família Anacardiaceae, sob a forma de extratos, como antiinflamatório e cicatrizantes para várias afecções, principalmente ginecológicas e ferimentos cutâneos ${ }^{6}$. Pesquisas com vistas à avaliação científica de sua eficácia terapêutica, têm mostrado evidente efeito antiinflamatório, cicatrizante, antiulcerogênico, antihistamínico, antibradicinina e analgésico $0^{6,7,8,9,10,11}$.

Através deste estudo, decidiu-se avaliar, do ponto de vista histológico, a ação do extrato aquoso da aroeira-dosertão na cicatrização da anastomose colônica, em ratos Wistar.

\section{Métodos}

A pesquisa foi realizada de acordo com as Normas Internacionais para a Pesquisa Biomédica em Animais (1990) conforme a Lei Federal $n^{\mathbf{0}}$ 6.638, de 08 de maio de $1979^{12}$. O projeto foi aprovado pela Comissão de Ética e Pesquisa em Animais, sob o protocolo número 32/04.

Foram utilizados 48 ratos (Mamalia Rodentia, Muridae, Rattus norvegicus albinus), machos, adultos, da linhagem Wistar, com peso médio 320 g, procedentes do Biotério Central da Universidade Federal do Ceará.

Os animais foram distribuídos ao acaso em dois grupos: A (controle) e B (aroeira) com 24 animais, cada. Cada grupo foi redistribuído em subgrupos, conforme a data da eutanásia, que foi nos dias 3, 7, 14 e 21 do experimento (A3, A7, A14, A21, B3, B7, B14 e B21).

\section{Procedimentos}

Após jejum de 12 horas, cada rato foi submetido a limpeza mecânica dos cólons, por enema evacuativo de solução salina a 0,9\%, seguida de anestesia geral inalatória com éter dietílico sob campânula. $\mathrm{O}$ animal foi imobilizado em decúbito dorsal sobre prancha de madeira, sendo feita anti-sepsia da parede abdominal com solução de polivinilpirrolidona-iodo, com $1 \%$ de iodo ativo e assepsia do campo operatório. Foi realizada laparotomia através de incisão mediana suprapúbica de $2 \mathrm{~cm}$ de extensão. Posteriormente, o cólon descendente foi identificado, isolado, exteriorizado e seccionado transversalmente, de modo completo, à distância de $2 \mathrm{~cm}$ da reflexão peritoneal. Em seguida, foi feita a reconstituição do trânsito colônico por anastomose colônica término-terminal, em plano único, com sutura contínua, utilizando-se fio de polipropileno 6-0.

A síntese da parede abdominal foi feita em dois planos com fio de polipropileno 000.

Após a recuperação anestésica, os ratos foram postos em gaiolas, em grupos de seis, com água e ração à vontade.

A cada 24 horas de pós-operatório, os ratos do grupo A recebiam enema de $1 \mathrm{ml}$ do veículo à base de carboximetilcelulose (CMC). Foi utilizado cateter de polietileno $\mathrm{n}^{\circ} 6 \mathrm{Fr}$., com extremidade distal fechada e quatro orifícios eqüidistantes em $0,5 \mathrm{~cm}$, em cada quadrante, no sentido distal-proximal que era introduzido até $4 \mathrm{~cm}$ da borda anal. O tratamento foi feito diariamente até a data da eutanásia. Os ratos do grupo B foram submetidos a procedimento semelhante utilizando-se enema de solução aquosa de aroeira a 10\% em veículo à base de CMC.

Nos dias 3, 7, 14 e 21 do experimento, seis animais de cada grupo foram submetidos à nova anestesia inalatória com éter dietílico sendo realizada relaparotomia para remoção de um segmento intestinal de $4 \mathrm{~cm}$, contendo a anastomose para estudo histológico.

\section{Avaliação histológica}

Todos os espécimes foram seccionados longitudinalmente, ao longo da borda antimesentérica, e dobrados no sentido distal-proximal, com a mucosa disposta externamente, à moda rocambole. Posteriormente foram fixados em solução de formalina a $10 \%$ e enviados ao Laboratório de Patologia do Departamento de Patologia e Medicina Legal da Faculdade de Medicina de Universidade Federal do Ceará para a rotina de preparo de cortes histológicos e de coloração pela hematoxilina-eosina (H-E) e tricrômico de Masson. A leitura foi feita em microscópio óptico, à magnitude de 40, 100 e 400 vezes (x) por um observador que desconhecia a que grupo e subgrupo pertencia o animal estudado.

O estudo histológico consistiu na avaliação morfológica da resposta inflamatória e morfométrica da densidade do colágeno do segmento intestinal na zona da anastomose. 
Utilizou-se o aumento de 40 e 100x para avaliar a morfologia da zona de anastomose, pela coloração H-E. O aumento de 400x foi utilizado para apreciação da densidade do colágeno, pela coloração do tricrômico de Masson.

\section{Avaliação morfológica}

O estudo morfológico visou analisar as condições de cicatrização utilizando os seguintes indicadores: presença de solução de continuidade, presença de crosta fibrinoleucocitária, quantificação indireta do edema, classificação do exsudato, quantificação da neoformação vascular e do tecido conjuntivo e o grau de reepitelização ${ }^{13}$. Para análise dos resultados obtidos, cada parâmetro recebeu uma pontuação, cujo somatório poderia variar de zero a 16 , conforme Figura 1.

\begin{tabular}{|l|c|c|c|c|}
\hline \multicolumn{5}{|c|}{ Escores } \\
\hline PARÂMETROS & $\mathbf{0}$ & $\mathbf{1}$ & $\mathbf{2}$ & $\mathbf{3}$ \\
\hline $\begin{array}{l}\text { Solução de } \\
\text { continuidade }\end{array}$ & $\mathbf{s i m}$ & - & & \\
\hline $\begin{array}{l}\text { Crosta fibrino- } \\
\text { leucocitária }\end{array}$ & $\mathbf{s i m}$ & - & & \\
\hline Edema & $>\mathbf{2 x}$ & $\mathbf{1 , 5 - 2 x}$ & $\mathbf{1 - 1 , 5 x}$ & - \\
\hline Exsudato & - & $\begin{array}{c}\text { neutrofilico } \\
\text { (aguda) }\end{array}$ & $\begin{array}{c}\text { misto } \\
\text { (subaguda) }\end{array}$ & $\begin{array}{c}\text { linfo- } \\
\text { monnonuclear } \\
\text { (crônica) }\end{array}$ \\
\hline $\begin{array}{l}\text { Neoformação } \\
\text { vascular }\end{array}$ & - & discreta & moderada & acentuada \\
\hline $\begin{array}{l}\text { Neoformação de } \\
\text { conjuntiva }\end{array}$ & - & discreta & moderada & acentuada \\
\hline Reepitelização & - & incompleta & completa & \\
\hline
\end{tabular}

FIGURA 1 - Escores usados na avaliação morfológica do processo cicatricial da anastomose colônica dos ratos, conforme Greca e col., 2000 cujo somatório poderia variar de zero a 16 , onde zero corresponderia ao mínimo de cicatrização e 16 ao máximo de cicatrização13.

A estimativa do edema foi obtida pela comparação entre a medida da parede intestinal na zona da anastomose em relação à medida da parede intestinal na zona distante $2 \mathrm{~cm}$ da anastomose (porção mais cranial).

\section{Avaliação da densidade do colágeno}

O estudo da densidade do colágeno foi realizado de modo convencional, utilizando-se ocular integradora, contendo retículo de 25 pontos, distribuídos geometricamente. A projeção do retículo sobre a área estudada permitiu a contagem dos pontos coincidentes ("hits") com as fibras colágenas ${ }^{14}$. Para tanto, convencionou-se examinar o corte histológico no sentido longitudinal, em relação à espessura da parede, inicialmente localizando-se a zona de anastomose a partir do epitélio até a serosa, examinando-se todos os campos presentes em suas bordas ${ }^{11}$, numa média de 10 campos por corte, totalizando cerca de 250 "hits” por rato.

\section{Análise estatística}

Para análise estatística dos resultados, utilizaram-se testes paramétricos e não paramétricos, levando-se em consideração a natureza das variáveis estudadas ${ }^{15}$. Para a análise morfológica, aplicou-se a análise de variância por postos de Kruskal-Wallis. Quando houve diferença significante, a análise foi complementada com o teste de Wilcoxon. Para a análise morfométrica, empregou-se o teste " $t$ ” de Student para diferença entre duas médias.

Em todos os testes, fixou-se em 0,05 ou 5\% o nível para rejeição da hipótese de nulidade, assinalando-se com um asterisco os valores significantes.

\section{Resultados}

Os achados da avaliação morfológica estão discriminados nas tabelas e gráficos abaixo.

\section{Escores}

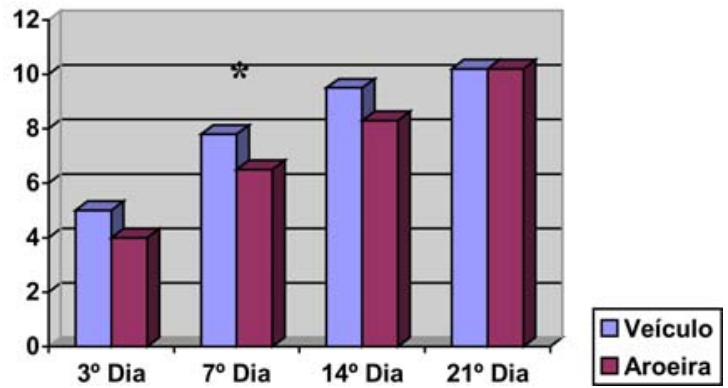

FIGURA 2 - Médias de valores atribuídos à análise morfológica de cortes histológicos corados por $\mathrm{H}-\mathrm{E}$, provenientes da anastomose colônica, nos dias 3, 7, 14 e 21 do experimento, em ratos que receberam enema de veículo ou aroeira a $10 \%$

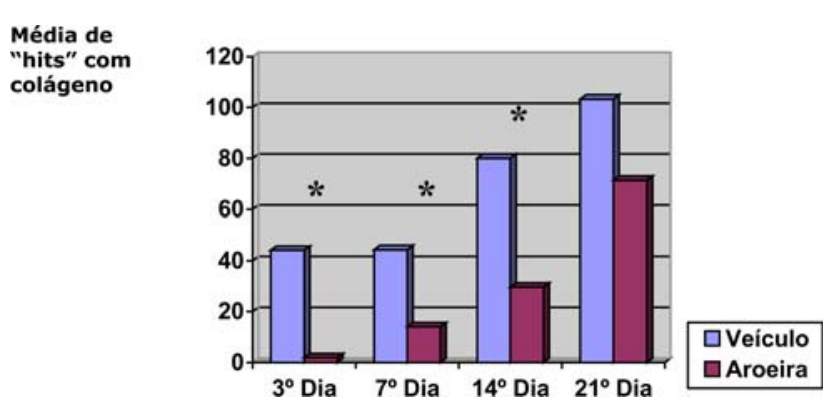

FIGURA 3 - Médias de "hits" contendo fibras colágenas nos campos estudados em cortes histológicos corados por tricrômico de Masson, provenientes da anastomose colônica, nos dias 3, 7, 14 e 21 do experimento, em ratos que receberam enema de veículo ou aroeira a $10 \%$ 
TABELA 1 - Valores atribuídos à análise morfológica de cortes histológicos corados por H-E, provenientes da anastomose colônica, nos dias 3, 7, 14 e 21 do experimento, em ratos que receberam enema de veículo e aroeira a 10\%

\begin{tabular}{|c|c|c|c|c|c|c|c|c|}
\hline \multirow{3}{*}{ Rato } & \multicolumn{8}{|c|}{ Grupos } \\
\hline & \multicolumn{4}{|c|}{ Veículo $^{(+)}$} & \multicolumn{4}{|c|}{ Aroeira $^{(\ddagger)}$} \\
\hline & Dia 3 & Dia 7 & Dia 14 & Dia21 & Dia 3 & $\operatorname{Dia7}{ }^{(*)}$ & Dia14 & Dia 21 \\
\hline 1 & 3 & 7 & 9 & 10 & 5 & 8 & 10 & 9 \\
\hline 2 & 5 & 8 & 11 & 11 & 3 & 6 & 7 & 10 \\
\hline 3 & 6 & 8 & 12 & 8 & 4 & 7 & 9 & 12 \\
\hline 4 & 4 & 8 & 8 & 9 & 4 & 6 & 8 & 9 \\
\hline 5 & 7 & 8 & 10 & 11 & 4 & 6 & 8 & 12 \\
\hline 6 & 5 & 8 & 7 & 12 & 4 & 6 & 8 & 9 \\
\hline Soma & 30 & 47 & 57 & 61 & 24 & 39 & 50 & 61 \\
\hline Média & 5,00 & 7,80 & 9,50 & 10,20 & 4,00 & 6,50 & 8,33 & 10,20 \\
\hline DP & 1,41 & 0,41 & 1,87 & 1,47 & 0,63 & 0,84 & 1,03 & 1,47 \\
\hline
\end{tabular}

$(*) p<0,05$ entre os grupos tratados

(†) Análise de variância por postos Kruskal-Wallis aplicada entre os dias do grupo Veículo $(3 \times 7 \times 14 \times 21)$ $\mathrm{H}_{\text {crítico }(5 \%)}=7,81$

$H_{\text {calculado }}=16,1^{*}$

Teste de Wilcoxon

$(3 \times 7 \times 14 \times 21)$

$\mathrm{W}_{\text {crítico }(5 \%)}=49,8$

$\mathbf{W}_{\text {calculado }}=56,5 *$

$\mathbf{W}_{\text {calculado }}=\mathbf{4 9}$

$\mathbf{W}_{\text {calculado }}=53,5 *$

Dia $3<7$; 14 e 21 .

Dia $7=14$ e $14=21$.

Dia $21>7$.

(₹) Análise de variância por postos Kruskal-Wallis aplicada entre os dias do grupo Aroeira $(3 \times 7 \times 14 \times 21)$

$\mathrm{H}_{\text {crítico(5\%) }}=7,81$

$H_{\text {calculado }}=19,81 *$

Teste de Wilcoxon

$(3 \times 7 \times 14 \times 21)$
$W_{\text {crítico }(5 \%)}=49,8$

$\mathbf{W}_{\text {calculado }}=\mathbf{5 2} *$

$\mathbf{W}_{\text {calculado }}=54 *$

$\mathbf{W}_{\text {calculado }}=57 *$

Dia $21>3$; 7 e 14 .

Dia $14>3$ e 7 .

Dia $7>3$.

(*) Teste da soma de ordens de Wilcoxon aplicado para comparação entre os grupos

Dia 3

$\mathbf{W}_{\text {calculado }}=30,5$

Veículo = Aroeira

Dia 7

$\mathbf{W}_{\text {calculado }}=25,0 *$

Veículo > Aroeira

$$
\mathrm{W}_{\text {crítico }(5 \%)}=28,16
$$

$$
\begin{aligned}
& \text { Dia } 14 \\
& \mathbf{W}_{\text {calculado }}=\mathbf{3 2 , 0} \\
& \text { Veículo = Aroeira } \\
& \text { Dia } 21 \\
& \mathbf{W}_{\text {calculado }}=\mathbf{3 9 , 0} \\
& \text { Veículo = Aroeira }
\end{aligned}
$$


TABELA 2 - Densidade de colágeno observada em cortes histológicos corados por tricrômico de Masson, provenientes de anastomose colônica, nos dias 3, 7, 14 e 21 do experimento, de ratos que receberam enema de veículo ou aroeira a $10 \%$

\begin{tabular}{|c|c|c|c|c|c|c|c|c|}
\hline \multirow{3}{*}{ Rato } & \multicolumn{8}{|c|}{ Grupos } \\
\hline & \multicolumn{4}{|c|}{ Veículo $^{(\dagger)}$} & \multicolumn{4}{|c|}{ Aroeira $^{(\neq)}$} \\
\hline & Dia 3 & Dia 7 & Dia 14 & Dia 21 & $\operatorname{Dia} 3^{(*)}$ & Dia $7^{(*)}$ & $\begin{array}{c}\text { Dia } \\
14^{(*)}\end{array}$ & Dia 21 \\
\hline 1 & 66 & 26 & 85 & 135 & 2 & 47 & 25 & 56 \\
\hline 2 & 43 & 58 & 83 & 87 & 6 & 8 & 9 & 24 \\
\hline 3 & 75 & 29 & 81 & 57 & 1 & 1 & 10 & 41 \\
\hline 4 & 43 & 19 & 94 & 119 & 0 & 6 & 22 & 85 \\
\hline 5 & 18 & 79 & 83 & 120 & 1 & 22 & 23 & 83 \\
\hline 6 & 20 & 55 & 54 & 102 & 1 & 0 & 89 & 139 \\
\hline Soma & 265 & 266 & 480 & 620 & 11 & 84 & 178 & 428 \\
\hline Média & 44,20 & 44,30 & 80,00 & 103,30 & 1,80 & 14,00 & 29,70 & 71,30 \\
\hline DP & 23,23 & 23,30 & 13,53 & 28,08 & 2,13 & 17,98 & 29,86 & 40,74 \\
\hline
\end{tabular}

$(*) p<0,05$ entre os grupos tratados

(†)Análise de variância por postos Kruskal-Wallis aplicada entre os dias do grupo Veículo $(3 \times 7 \times 14 \times 21)$ $\mathrm{H}_{\text {crítico(5\%) }}=7,81$

$H_{\text {calculado }}=14,28 *$

Teste de Wilcoxon

$(3 \times 7 \times 14 \times 21)$

$W_{\text {crítico(5\%) }}=49,8$

$\mathbf{W}_{\text {calculado }}=54 *$

$\mathbf{W}_{\text {calculado }}=51 *$

Dia $14>3=7$.

Dia $21>3$; 7 e 14 .

(‡) Análise de variância por postos Kruskal-Wallis aplicada entre os dias do grupo Aroeira $(3 \times 7 \times 14 \times 21)$

$\mathrm{H}_{\text {critico(5\%) }}=7,81$

$H_{\text {calculado }}=15,64 *$

Teste de Wilcoxon

$(3 \times 7 \times 14 \times 21)$

$\mathrm{W}_{\text {critico }(5 \%)}=49,8$

$\mathrm{W}_{\text {calculado }}=47,5$

$\mathrm{W}_{\text {calculado }}=\mathbf{4 9 , 5}$

$\mathbf{W}_{\text {calculado }}=\mathbf{5 1} *$

Dia $3=7$.

Dia $7=14$.

Dia $21>3$; 7 e 14 .

(*) Teste para diferença de duas médias " $t$ " de Student aplicado para comparação entre os grupos

Dia 3

$t_{\text {calculado }}=\mathbf{4 , 4 5 *}$

Veículo > Aroeira $10 \%$

Dia 7

$\mathbf{t}_{\text {calculado }}=2,53 *$

Veículo > Aroeira 10\%

$$
\mathrm{t}_{\text {critico(5\%) }}=1,81
$$

Dia 14

$t_{\text {calculado }}=3,76 *$

Veículo > Aroeira 10\%

Dia 21

$t_{\text {calculado }}=1,58$

Veículo $=$ Aroeira $10 \%$ 


\section{Discussão}

A aroeira-do-sertão é um fitoterápico de fácil aquisição, baixo custo e de uso popular no Nordeste do Brasil. Suas propriedades cicatrizante e antiinflamatória foram demonstradas em várias pesquisas ${ }^{6,7,8,9,10,11}$, porém, são escassos trabalhos sobre sua ação em anastomoses colônicas. Neste estudo, foram investigados as influências da aroeira-do-sertão sobre a cicatrização de anastomoses colônicas, em ratos. Diversos aspectos morfológicos e a densidade do colágeno foram avaliados, com o intuito de determinar o grau de interferência da aroeira-do-sertão neste processo.

Para a confecção das anastomoses colônicas, foi optado pela sutura contínua, em plano único. Este é um método simples, rápido e econômico, promovendo impermeabilidade e pouca reação inflamatória tecidual, sendo tão seguro quanto a sutura com pontos separados ${ }^{16}$. O fio utilizado foi o polipropileno 6-0. Os fios monofilamentares são preferíveis aos multifilamentares, pois estes últimos favorecem o surgimento de infecções, acentuando a reação inflamatória ${ }^{17}$.

A aroeira-do-sertão foi utilizada na concentração a $10 \%$, sob a forma de enemas, pois há comprovação experimental de sua eficácia farmacológica no sistema digestório, nesta apresentação. Utilizou-se o veículo viscoso por determinar maior permanência das substâncias em contato com a mucosa do cólon, e porque se mostrou substância inerte em estudos anteriores, quando utilizado isoladamente ${ }^{11}$

Os dias escolhidos para avaliação histológica tiveram como base os estudos de Herrmann e col. (1964) sobre a cicatrização de anastomoses colônicas em ratos sacrificados a intervalos desde três horas até um ano após a operação. Os eventos histológicos do processo cicatricial apresentaram três fases distintas, porém superpostas, a saber: fase exsudativa - resposta inflamatória aguda (0 - 4 dias); fase proliferativa - predomínio da fibroplasia (3-14 dias); e fase de reorganização e remodelagem - maturidade do colágeno (10 - 180 dias ou mais) ${ }^{3}$.

O papel da fase inflamatória, incluindo a migração de neutrófilos para os tecidos, tem sido debatido na literatura, e a maioria dos pesquisadores é de opinião que neutrófilos têm um importante papel eliminando debris, protegendo da infecção e liberando substâncias promotoras da cicatrização. O deslocamento de neutrófilos se inicia imediatamente após a lesão tecidual, atingindo um pico de concentração em apenas 12 horas $^{18}$.

A proliferação fibroblástica e endotelial dá origem ao tecido de granulação. A síntese de colágeno pela ação dos fibroblastos, é mais intensa em torno do quinto ao sétimo dia de pós-operatório. A força de tensão da ferida aumenta com a formação de fibras colágenas e a adesão destas fibras entre si atinge o máximo entre o décimo quarto e o décimo sexto dia de pós-operatório ${ }^{1,18}$.

A lesão tecidual com cicatrização por primeira intenção (incisão seguida de sutura) causa a morte de um número limitado de células epiteliais e de tecido conectivo, assim como provoca a solução de continuidade da membrana basal epitelial. O espaço da incisão fica repleto de coágulos, fibrina e leucócitos (crosta fibrino-leucocitária). Em 24 horas os neutrófilos migram para as bordas da incisão a fim de remover essa crosta através de fagocitose. A parede intestinal torna-se cada vez mais espessada pois o aumento da permeabilidade vascular provoca edema e há intensa atividade mitótica na membrana basal, assim como migração de grande quantidade de células do processo inflamatório (exsudato) para a região. Aos poucos, o exsudato agudo é gradualmente substituído por exsudato mononuclear (principalmente às custas de macrófagos e linfócitos) e tecido de granulação (neoformação vascular e fibroblastos), além do que inicia-se a deposição de colágeno pelos fibroblastos nas margens da incisão. Por volta do $14^{\circ}$ dia, já existem sinais de reepitelização. O edema, o infiltrado neutrofílico e a vasodilatação já desapareceram e a deposição do colágeno é intensa. Esse processo evolui até a reepitelização completa (fechamento da solução de continuidade), com conseqüente diferenciação das células do epitélio, seguida de maturação de sua arquitetura. Meses após a lesão tecidual a força de tensão no tecido reparado atinge o máximo ${ }^{19}$.

A avaliação morfológica utilizada (Figura 1), já descrita por Greca e col. (2000), contempla vários aspectos do processo descrito acima e avalia as condições de cicatrização através de escores dados aos seguintes indicadores: presença de solução de continuidade, presença de crosta fibrino-leucocitária, evolução do tipo de exsudato (agudo, subagudo e crônico), quantificação do edema, intensidade da neoformação vascular e conjuntiva e grau de reepitelização ${ }^{13}$.

A evolução morfológica (Tabela 1) do processo cicatricial das anastomoses colônicas se deu de forma progressiva entre as fases mais precoces ( $3^{\circ}$ dia) e as fases mais tardias ( $\left.21^{\circ} \mathrm{dia}\right)$, evidenciando-se diferenças significantes entre os dias 7 e 21, porém sem alterações significantes entre os dias 7 e 14, nem entre os dias 14 e 21 . Entretanto, no grupo Aroeira, observou-se diferenças significantes entre os dias 3 e 7, dias 7 e 14 e dias 14 e 21, supondo-se não haver superposição das fases. Já a comparação intergrupos (Figura 2) mostra que no dia 3 do estudo, os valores atribuídos ao processo cicatricial foram semelhantes. Houve significância apenas no dia 7, quando o grupo estudado apresentou menor escore, revelando atraso no processo cicatricial nesta fase. Há em seguida, equiparação a partir do dia 14. Assim como os corticosteróides e outros antiinflamatórios, a aroeira pareceu inibir a evolução das fases iniciais do processo cicatricial por diminuir a migração de leucócitos para a área lesada, diminuindo assim a concentração de substâncias quimiotáxicas e citocinas nessa região ${ }^{20}$.

A deposição do colágeno (Tabela 2) nas anastomoses colônicas foi bastante reduzida nos dias 3 e 7, pois nessa fase não havia fibroblastos suficientes na zona de reparação. Essa deposição foi progressivamente maior nos dias 14 e 21. No grupo Aroeira, houve maior deposição de colágeno no $21^{\circ}$ dia, porém não se observou diferença significante na deposição do colágeno entre os dias 3, 7 e 14. Na comparação entre os grupos (Figura 3), a deposição do colágeno no grupo aroeira foi menor, nos dias 3, 7 e 14, em relação ao grupo controle, o que sugere que a aroeira promove inibição na deposição de colágeno pelos fibroblastos ou retardo na migração de fibroblastos para a 
zona de reparo. O colágeno não é uma proteína inerte, pois está em constante equilíbrio entre lise e síntese. Alterações na quantidade e qualidade do colágeno presente no intestino, sobretudo na submucosa, influenciam profundamente a integridade da anastomose ${ }^{19}$.

Pela análise histológica, a aroeira-do-sertão retardou a evolução das fases iniciais do processo cicatricial por uma provável ação antiinflamatória. Também houve retardo na deposição de colágeno. Tardiamente (no dia 21), a aroeira não causou alterações histológicas no processo cicatricial. Este achado aparentemente contraditório pode ser explicado porque a fase inflamatória da cicatrização é uma etapa essencial deste processo ${ }^{5}$. Ela desencadeia uma série de eventos celulares e bioquímicos que ocorrem numa seqüência organizada e complexa pelo aumento da permeabilidade vascular, quimiotaxia das células da circulação para dentro do ambiente da ferida, liberação local de citocinas e fatores do crescimento e ativação de células migrantes ${ }^{5}$. Uma redução excessiva da resposta inflamatória poderia então prejudicar a cicatrização, por retardar as demais fases do processo, sem necessariamente impedir que ela ocorra ${ }^{4,5}$. Esses achados suscitam dúvidas sobre os mecanismos pelos quais este complexo fitoterápico age e portanto estudos aprofundados sobre esses mecanismos são necessários.

\section{Conclusão}

O extrato aquoso da aroeira-do-sertão interfere no processo cicatricial de anastomose colônica, em ratos Wistar, inibindo a fase inflamatória (dia 7) e interferindo na deposição de colágeno (dias 3, 7 e 14), porém sem afetar o resultado final da cicatrização.

\section{Referências}

1. Sakallioglu, A.E.; Yagmurlu, A.; Dindar, H.; Hasirci, N.; Renda, N.; Deveci, M.S. Sustained local application of low-dose epidermal growth factor on steroid-inhibited colonic wound healing. J. Pediatr. Surg. 1994;39:591-5.

2. Kaplan, M.; Mentes, B.B.; Tatlicioglu, E.; Kayhan, B.; Aybay, C. Effect of mucosal immunomodulation with fed cholera toxin on healing of experimental colonic anastomosis. Dis. Colon Rectum. 2002;45:819-25.

3. Herrmann, J.B.; Woodward, S.C.; Pulaski, E.J. Healing of colonic anastomosis in the rat. Surg. Gynecol. Obstet. 1964;119:269-75.

4. Matsboom, W.J.; Hendriks, T.; Van Eteren, P.; De Boer, H.H. The influence of NSAIDs on experimental intestinal anastomosis. Dis. Colon Rectum. 1991;34:236-43.

5. Sirimarco, M.T.; Zucoloto, S.; Aprille, F. Estudo comparativo dos efeitos de dois corticosteróides sintéticos, deflazacort e prednisona, na cicatrização de anastomoses colônicas de ratos. Rev. Bras. Coloproct. 2001;21:167-95.

6. Viana, G.S.B.; Matos, F.J.A.; Bandeira, M.A.M.; Rao, V.S.N. Aroeira-do-sertão (Myracrodruon urundeuva Fr. All.) Estudo botânico, farmacognóstico, químico e farmacológico. Fortaleza: UFC; 1995.
7. Menezes, A.M.S. Atividade antiinflamatória e antiulcerogênica de Astronium urundeuva engl. [Dissertação - Mestrado]. Universidade Federal do Ceará; 1986.

8. Rao, V.S.N.; Menezes, A.M.S.; Vasconcelos, F.A.; Almeida, F.R.C.; Fonteles, M.C. Effect of Astronium urundeuva engl. (aroeira) in experimental colitis. Braz. J. Med. Biol. Res. 1986;19:568.

9. Rao, V.S.; Viana, G.S.B.; Menezes, A.M.S.; Gadelha, M.G.T. Studies on the anti-ulcerogenic activity of Astronium urundeuva engl. II. Aqueous extract. Braz. J. Med. Biol. Res. 1987;20:803-5.

10. Viana, G.S.B.; Bandeira, M.A.M.; Moura, L.C.; Souza Filho, M.V.P.; Matos, F.J.A.; Ribeiro, R.A. Analgesic and antiinflammatory effects of the tannine fraction from Myracrodruon urundeuva Fr. All. Phytother. Res. 1997;11:118-22.

11. Rodrigues, L.V.; Ferreira, F.V.; Regadas, F.S.; Matos, D.; Viana, G.S. Morphologic and morphometric analyses of acetic acid-induced colitis in rats after treatment with enemas from Myracrodruon urundeuva Fr. All. (Aroeirado-Sertão). Phytother. Res. 2002;16:267-72.

12. Brasil. Lei Federal n. 6.638, de 8 de maio de 1979. Estabelece normas para a prática didático-científica da vivissecção de animais e determina outras providências. In: Brasil. Coleção de leis de 1979: atos legislativos do poder executivo. Leis de abril a junho. Brasília, Departamento de Imprensa nacional, 1979. p. 33-4.

13. Greca, F.H.; Biondo-Simões, M.L.P.; De Paula, J.B.; Noronha, L.; Cunha, L.S.F.; Baggio, P.V.; Bittencourt, F.O. Correlação entre o fluxo sanguíneo intestinal e a cicatrização de anastomoses colônicas: estudo experimental em cães. Acta. Cir. Bras. 2000;15:88-94.

14. Weibel, E.R.; Kristler, G.S.; Scherle, W.F. Practical stereological methods for morphometric cytology. J. Cell Biol. 1966;30:23-38.

15. De Campos, H. Estatística experimental não paramétrica. 4ed. Piracicaba: Fundação de estudos agrários Luis de Queiroz; 1983.

16. Skakun, G.B.; Reznick, R.K.; Bailey, H.R.; Smith, K.W.; Max, E. The single-layer continuous polypropylene colon anastomosis. A prospective assessment using watersoluble contrast enemas. Dis. Colon Rectum. 1988;31:163-8.

17. Katz, S.; Izhar, M.; Mirelman, D. Bacterial adherence to surgical sutures: a possible factor in suture induced infection. Ann. Surg. 1981;194:35-41.

18. Clark, R.A.F. Wound repair. Overview and general considerations. In: Clark, R.A.F. The molecular and cellular biology of wound repair. 2ed. New York: Plenum Press; 1996. p. 3-50.

19. Cotran, R.S.; Robbins, S.L.; Kuman, V. Inflammation and repair. In: Cotran, R.S. Pathologic basis of disease. 5ed. Philadelphia: W. B. Saunders Company, 1994. p. 51-92.

20. Fauci, A.S.; Dale, D.C.; Balow, J.E. Glucocorticosteroid therapy: mechanisms of action and clinical considerations. Ann. Intern. Med. 1976;84:304-15. 
Correspondência:

Annya Costa Araújo de Macedo Goes

Rua Dr. Thomaz Pompeu, 171 Apto 1203 Meireles

Fortaleza, Ceará, 60160-080, Brasil

Tel. +55852483231

E-mail: annya.goes@terra.com.br
Conflitoto de interesse: nenhum Fonte de financiamento: nenhum

Recebimento: 27/10/2004

Revisão: 05/12/2004

Aprovação: 18/01/2005

\section{Como citar este artigo:}

Goes ACAM, Rodrigues LV, MenezesDB, Grangeiro MPF, Cavalcante ARMS. Análise histológica da cicatrização da anastomose colônica, em ratos, sob ação de enema de Aroeira-do-sertão (Myracrodruon urundeuva fr. all.) a 10\%. Acta Cir Bras [serial online] 2005 Mar-Abr; 20(2). Disponível em URL: http://www.scielo.br/acb

Figuras coloridas disponíveis em http://www.scielo.br/acb 